\title{
Fabrication of Gelatin Nano-Capsules Incorporate Ferula assa-foetida Essential Oil With Antibacterial and Antioxidant
}

\author{
Somayeh Jahani ${ }^{1}$; Amin Shakiba ${ }^{2, *}$; Leila Jahani $^{1}$ \\ ${ }_{1}^{1}$ Infectious Diseases and Tropical Medicine Research Center, Zahedan University of Medical Sciences, Zahedan, IR Iran \\ ${ }^{2}$ Department of Biotechnology, University of Shiraz, Shiraz, IR Iran \\ *Corresponding author: Amin Shakiba, Department of Biotechnology, University of Shiraz, Shiraz, IR Iran. E-mail: amin_shakiba01@yahoo.com \\ Received: January 3, 2014; Accepted: April 9, 2014
}

\begin{abstract}
Background: Manufacturing Gelatin nano-capsules merged with Ferula assa-foetida essential oil, antioxidant and antibacterial properties to produce drugs with properties targeted drug delivery to the body.

Objectives: In this study, we proved that gelatin nano-capsules grafted with F. assa-foetida essential oil have excellent physical, well as good antioxidant and antibacterial activity, which is suitable for producing nano-capsules of antioxidant antibacterial drug.

Materials and Methods: In this experimental study, gelatinnano-capsules were prepared from gelatin solutions (10\% w/v) containing F. assa-foetida essential oil (FAO) (2, 4, 6 and $8 \% \mathrm{w} / \mathrm{w})$, glycerol $(25 \% \mathrm{w} / \mathrm{w})$ as plasticizer and glutaraldehyde $(2 \% \mathrm{w} / \mathrm{w})$ as cross-linker. The morphology, antioxidant and antibacterial properties of the nano-capsules were achieved according to American Society for Testing and Materials.

Results: Gelatin nano-capsules exhibited low antioxidant activity while gelatin nano-capsules incorporated with FAO exhibited excellent antioxidant properties. The nano-capsules incorporated with FAO also exhibited excellent antibacterial properties against both Grampositive and Gram-negative bacteria.

Conclusions: According to the results, gelatin nano-capsules are good nominations for a variety of antibiotic replacement industrial. The nano-capsules as well as due to the risk of bacterial resistance stay safe. The nano-capsules according to the origin of the whole plant do not have any negative effects on the body.
\end{abstract}

Keywords: Gelatin; Capsules; Ferula assa-foetida; Antioxidant; Antibacterial

\section{Background}

Gelatin is a soluble protein obtained by partial hydrolysis of collagen, the main insoluble fibrous protein constituent on bones, cartilages and skins [1]. Unique collagen and gelatin structures influence their physical properties, such as solubility, swelling, water uptake, moisture absorption, water evaporation, transparency, color, odor, gel strength and thermal stability. Physical properties of gelatin itself influence gelatin quality and potential applications in food and pharmaceutical industry $[2,3]$. The food and pharmaceutical applications of gelatin are based mainly on the gel-forming, film-forming and viscoelastic properties. Recently, an increasing number of new applications have been found for gelatin in products, such as emulsifiers, foaming agents, colloid stabilizer, hydrogels, fining agents, packaging materials, wound dressing and micro-encapsulating agents $[4,5]$. Gelatin has been reported to be one of the first materials used as carrier of bioactive components. Enrichment of nano-capsules with natural antioxidants and/or antimicrobial functional properties of these nano-capsules will increase. There is growing interest in using plant extracts as natural sources of antioxidant/antibacterial compounds in the formulation of gelatin nano-capsules
[6-9]. In this context, plant essential oils and their main components are gaining a wide interest in health industry for their potentials as antioxidant and antimicrobial agents, as they are generally recognized as safe (GRAS) $[10,11]$. To our knowledge there is no report on the on the antioxidant and antimicrobial activity of gelatin films incorporated with Ferula assa-foetida. F. assa-foetida is a useful plant in the Apiaceous family. In traditional medicine the plant is used for the treatment of different diseases, such as asthma, epilepsy, stomachache, flatulence, intestinal parasites, weak digestion and influenza $[12,13]$. In this study the gelatin nano-capsules with antioxidant and antimicrobial activities were prepared from gelatin solutions containing different $F$. assa-foetida essential oil concentrations. Antioxidant activities of the gelatin nano-capsules incorporated with $F$. assa-foetida essential oil were examined using 2'-azino-di (3 - ethylbenzthiazoline -6-sulfonate) (ABTS) decolorization. The gelatin nano-capsules containing F. assa-foetida essential oil were individually tested against two Gram-negative bacteria (Pseudomonas aeroginosa and Escherichia coli) and two Gram-positive bacteria (Staphylococcus aureus and Bacillus subtilis) commonly found in human pathogenesis.

Copyright (C) 2015, Zahedan University of Medical Sciences. This is an open-access article distributed under the terms of the Creative Commons Attribution-NonCommercial 4.0 International License (http://creativecommons.org/licenses/by-nc/4.0/) which permits copy and redistribute the material just in noncommercial usages, provided the original work is properly cited. 


\section{Objectives}

In this study, we proved that gelatin nano-capsules grafted with $F$. assa-foetida essential oil have excellent physical, well as good antioxidant and antibacterial activity, which is suitable for producing nano-capsules of antioxidant antibacterial drug.

\section{Materials and Methods}

\subsection{Preparation of Gelatin Nano-Capsules Forming Solutions}

In this experimental study, to prepare gelatin nanocapsules forming solutions, $10 \mathrm{~g}$ of bovine gelatin powder (Sigma-Aldreich, Germany) dissolved into $80 \mathrm{~mL}$ of distilled water at ambient temperature and temperature increased to $60^{\circ} \mathrm{C}$ using a Hotplate-stirrer and the mixture was stirred for 30 minutes at this temperature. After cooling to $37^{\circ} \mathrm{C}, \mathrm{F}$. assa-foetida essential oil (obtained by hydro-distillation) with different concentration $(2,4,6$, and $8 \% \mathrm{w} / \mathrm{w}$ based on the weight of the gelatin powder $=1$, 2,4 , and $8 \mathrm{mg} / \mathrm{mL}$ based on the gelatin solutions) as antimicrobial agent, glycerol ( $25 \% \mathrm{w} / \mathrm{w}$ based on the weight of the gelatin powder $=25 \mathrm{mg} / \mathrm{mL}$ based on the gelatin solution)(Merck, Germany) as plasticizer and glutaraldehyde $(2 \% \mathrm{w} / \mathrm{w}$ based on the weight of the gelatin powder $=2$ $\mathrm{mg} / \mathrm{mL}$ based on the gelatin solution) (Merck, Germany) as cross-linker were added to gelatin solutions and then distilled water was added to final of $100 \mathrm{~mL}$ and homogenized $[14,15]$.

\subsection{Preparation of Gelatin Nano-Capsules}

To cast the films, $10 \mathrm{~mL}$ of gelatin film forming solutions containing different $F$. assa-foetida essential oil concentrations were transferred into the polyester Petri dish (Farazbin Kimia Co., Teheran, Iran, the radius of $74 \mathrm{~mm}$ ) and placed at room temperature until films were dried. Then grind the dried film to be produced gelatin nanocapsules. Ferula asa-foetida essential oil reserves are in the nano-capsules.

\subsection{Surface Morphology and Nano-Capsules Mi- crostructure}

The test was conducted at the Department of Materials Engineering, Shiraz University. Silver particles coated with gelatin nano-capsules of $F$. assa-foetida essential oil.

Antioxidant activity of nano-capsules: Antioxidant activities of the films were determined by decolorization method with 2, 2'-azino-di (3-ethylbenzthiazoline-6-sulfonate) (ABTS, Sigma, Germany) [16]. The method was modified to detect the continuous antioxidant release from films. The release tests were performed in 24 well plates. Briefly, 20 mg powder nano-capsules from different parts of the nano-capsules containing 2, 4, 6 and $8 \%$ of the F. assa-foetida essential oil was added to $2.0 \mathrm{~mL}$ of diluted ABTS radical solution (7 mM ABTS and $2.54 \mathrm{mM}$ potassium persulfate, A734 = $1 \pm 0.1$ ). Nano-capsules without F. assa-foetida essential oil were used as blank. The program was adjusted to record the absorbance values after shaking the 24 well plates for 30 seconds using a plate reader (Bio Tek Elx 808, Winooski, VT, 05403, USA). The data was recorded up to steady state was reached for each sample. A standard curve of ascorbic acid ranging from 0.44 to $15.76 \mathrm{mg} / \mathrm{mL}$ was prepared. Antioxidant activity was expressed as mg ascorbic acid equivalents per gram of films using standard curve.

\subsection{Antibacterial Activity of Gelatin Nano-Cap- sules Using Colony Counting}

All microorganisms obtained from the Persian type culture collection (PTCC), Tehran, Iran. The powder nano-capsules were individually tested against two Gram-negative bacteria [P. aeruginosa PTCC 1074 (ATCC 9027 and E. coli PTCC 1330 (ATCC 8739)] and two Gram-positive bacteria [S. aureus PTCC 1112 (ATCC 6538) and B. subtilis PTCC 1023 (ATCC 6633)]. The bacterial colony counting assays were carried according to Clinical and Laboratory Standards Institute (CLSI) and ASTM G22-76. Bacteria strains were suspended in LB media and the densities were adjusted to 0.5 McFarland standards at $640 \mathrm{~nm}\left(10^{8} \mathrm{CFU} / \mathrm{mL}\right)$ and then diluted to $10^{5} \mathrm{CFU} / \mathrm{mL}$ with LB. Twenty milligram powder nano-capsules in a $10 \mathrm{~mL}$ liquid culture containing $10 \mu \mathrm{L}$ microbe cultures. Then, the sample was incubated at $37^{\circ} \mathrm{C}$ for 24 hours (Shaking Incubator, Shin Saeng, Fine Tech, Korea). From the incubated samples, a $100 \mu \mathrm{L}$ solution was taken and diluted with the appropriate dilution factor and the final diluted microbe solution was plated and distributed onto nutrient agar plate (Farazbin Kimia Co., Tehran, Iran). The plates cultured with the powder nano-capsules without $F$. assa-foetida essential oil under the same condition were used as control. All plates were incubated at $37^{\circ} \mathrm{C}$ for 24 hours and the numbers of colonies that formed were counted. The antibacterial efficacy of the powder nanocapsules was calculated according to the following equation [17]. Colony reduction $(\%)=[($ Number of colony in test samples - Number of colony in control)/ Number of colony in test samples] $\times 100$.

\subsection{Statistical Analysis}

Data are expressed as the means plus/minus standard deviations of at least three independent experiments. The significant differences between treatments were analyzed by one-way analysis of variance (ANOVA) and Duncan tests at $\mathrm{P}<0.05$ using statistical package for the social sciences (SPSS-17, Abaus Concepts, Berkeley, CA) and Prism 5 (Graph Pad, San Diego, USA) software's.

\section{Results}

\subsection{Plant Materials}

GC-MS analysis of the F. assa-foetida essential oil indicat- 
Jahani S et al.

ed the main components were $\beta$-pinene (47.1\%), $\alpha$-pinene (21.36\%), 1, 2-dithiolane (18.6\%), nitrite propyl (3.67\%), thionol (2.64\%) and cis- $\beta$-ocimene (2.43\%).

Antioxidant activity of nano-capsules: Antioxidant activity of the gelatin nano-capsules incorporated with different $F$. assa-foetida essential oil concentrations was determined by ABTS decolorization method and expressed as mg ascorbic acid equivalent per gram of nano-capsules (Figure 1). The gelatin nano-capsules without $F$. assa-foeti$d a$ essential oil showed very low activity against the ABTS decolorization. The antioxidant activity was expressed milligram ascorbic acid equivalent (AAE) per gram incorporating different concentrations of $F$. assa-foetida essential oil. Mean values with different letters within a column are significantly different by Duncan's multiple range tests at $(\mathrm{P}<0.05)$.

\subsection{Morphology of Nano-Capsules}

SEM analyses of the results are shown in Figures 2 - 4. The SEM images at magnifications of $(100 \times)$ gelatin nanocapsules containing different $F$. assa extract of bitter are more compact than $4 \%$ nano-gelatin concentrations ( 0 , 4 and 8) of F. assa-foetida of bitter. Gelatin nano-capsules with $8 \%$ of Ferula capsules gelatin films of F. assa-foetida bitter are very less squeezed. Due to the hydrophobic nature of F. assa-foetida they bonds with second hydrophobic gelatins which this causes crosslinking of the film is broken and links between Ferula assa-foetida and second's gelatin is more intense and gelatin nano-capsules containing a larger percentage of the F. assa-foetida of bitter are more compact $F$. assa-foetida of bitter towards nano-capsules without the additional bonds with the hydrophobic domains formed gelatin. As a result, increases the concentration of F. assa-foetida carrier oil gelatin capsules are more compact and can store larger percentage of F. assa-foetida extract.

\subsection{Antibacterial Activity of Gelatin Nano-Cap- sules}

Thus gelatin films incorporated with F. assa-foetida essential oil are effective against both Gram-positive and Gram-negative bacteria while they are more effective to Gram-positive bacteria rather than to Gram-negative bacteria. The results of colony reduction percentage are summarized in (Figure 5).

According to the results obtained, the antibacterial activity of gelatin nano-capsules containing different F. assa essential oil concentrations was greatest against S. aureus followed by B. subtilis followed by E. colli and then by $p$. aeroginosa. F. assa-foetida essential oil gradually released from films to the solution and penetrates to the cell membranes and disrupts membrane structure and finally cell death. Antibacterial activity was expressed as bacterial growth reduction in the presence of nano-capsules with different Ferula oil concentration.

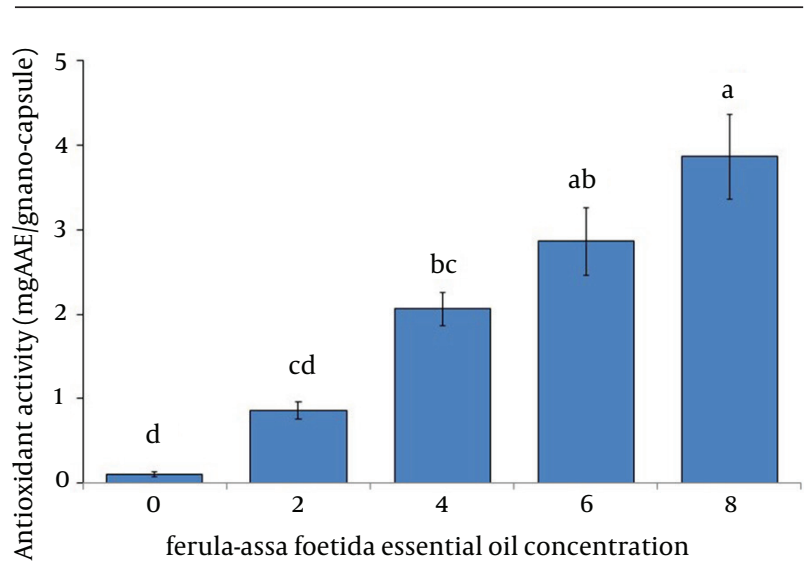

Figure 1. Antioxidant Activity of Gelatin Nano-Capsules Incorporated with F. Assa-Foetida oil

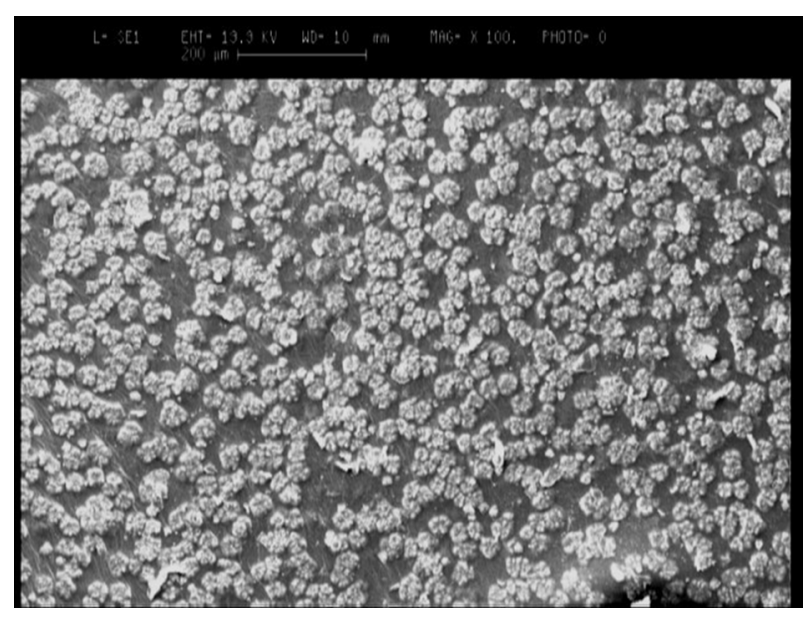

Figure 2. SEM Image of the $100 \times$ Power of Gelatin Films without F. AssaFoetida Extract of Bitter

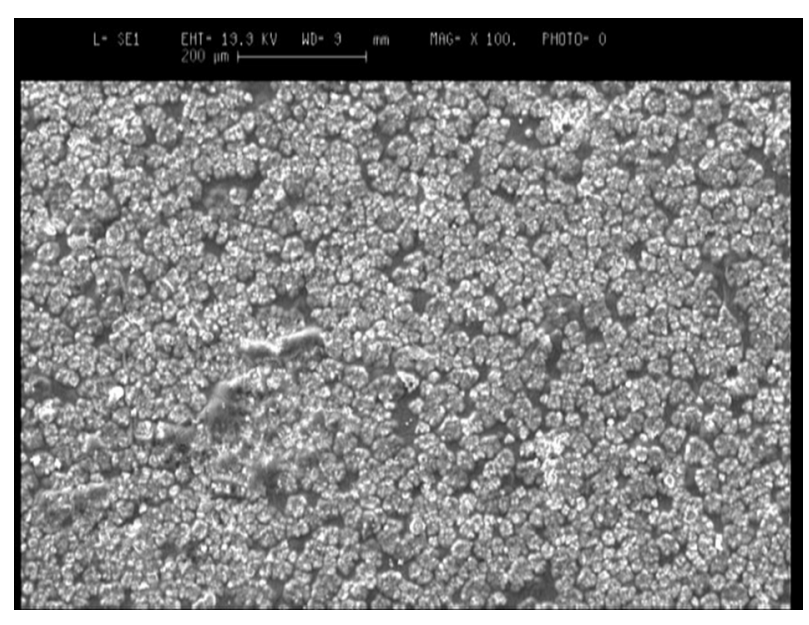

Figure 3. SEM Image of the $100 \times$ Power of Gelatin Films with $4 \%$ F. AssaFoetida Extract of Bitter 


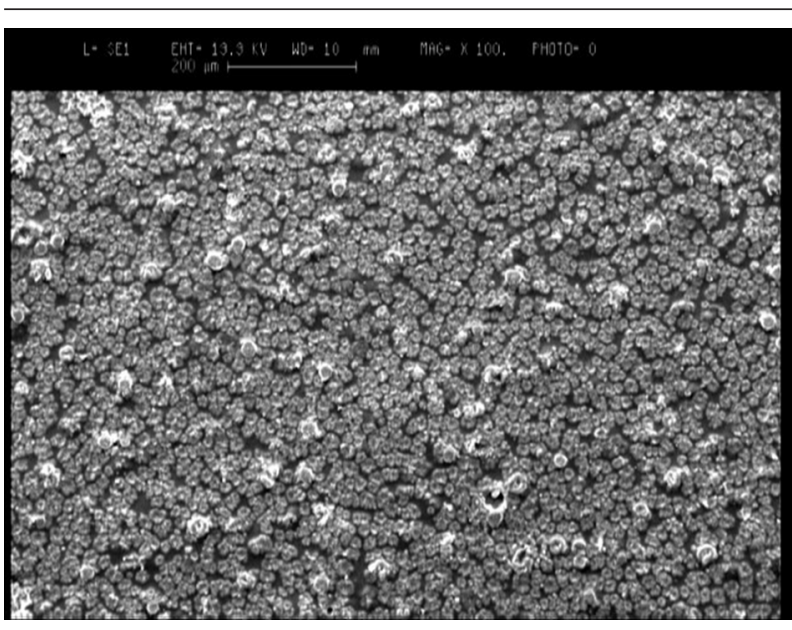

Figure 4. SEM Image of the $100 \times$ Power of Gelatin Films with $8 \%$ F. AssaFoetida Extract of Bitter

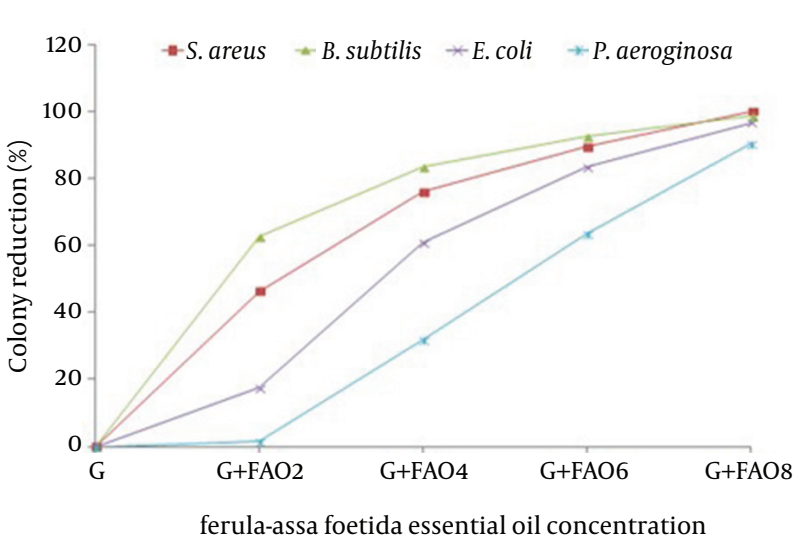

Figure 5. Antibacterial Activity of Gelatin Nano-Capsules Incorporated with F. Assa-Foetida oil Using Viable Colony Counting

Mean values with different letters within a column are significantly different by Duncan's multiple range tests at $(\mathrm{P}<0.05)$.

\section{Discussion}

According to the results, gelatin nano-capsules are good nominations for a variety of antibiotic replacement industrial. Previous study reported the main components of the F. assa-foetida essential oil, were (E)-1-propenyl-secbutyl disulfide (40\%), (Z)-1-propenyl-sec-butyl disulfide (8.7\%), germacrene B (7.8\%), $\alpha$-pinene (5.9\%) and $\beta$-pinene (5\%) [15]. Thus, the F. assa-foetida essential oil analyzed in this research had roughly same components with other previously analyzed $F$. assa-foetida essential oil, however, were showed important differences in their quality and quantity of the components. Various studies have examined antioxidant properties of peptides derived from gelatin in different sources. These studies have shown peptides derived from enzymatic hydrolysis of gelatin are lipid peroxidation inhibitors, free radical scavengers, and transition metal ion chelators. The antioxidative properties of peptides are related to their amino acid composition, molecular weight structure, and hydrophobicity $[18,19]$.

The gelatin nano-capsules containing different F. assafoetida essential oil concentrations decolorize ABTS dosedependently. Fish skin gelatin film incorporated with citrus essential oils [16] were exhibited strong antioxidant activity, which similar to our results. These antioxidant activity may be attributed, at least in part, to the presence of phenols, flavonoids, sesquiterpenes and sulfur-containing compounds. These studies have shown peptides derived from enzymatic hydrolysis of gelatin are lipid peroxidation inhibitors, free radical scavengers and transition metal ion chelators. The antioxidative properties of peptides are related to their amino acid composition, molecular weight, structure and hydrophobicity $[4,19]$.

The gelatin nano-capsules containing different $F$. assa-foetida essential oil concentrations decolorize ABTS dose-dependently. Fish skin gelatin film incorporated with citrus essential oils [16] were exhibited strong antioxidant activity, which similar to our results. This antioxidant activity may be attributed, at least in part, to the presence of phenols, flavonoids, sesquiterpenes and sulfur-containing compounds in the F. assa-foetida essential oil $[18,20]$. These results recommended that gelatin nano-capsules incorporated with $F$. assa-foetida essential oil could be promising candidate for safe radical scavenger in the body. Due to the hydrophobic nature of F. assa-foetida they bonds with second hydrophobic gelatins which this causes crosslinking of the film is broken and links between $F$. assa-foetida and second's gelatin is more intense and gelatin nano-capsules containing a larger percentage of the F. assa-foetida of bitter are more compact $F$. assa-foetida of bitter towards nano-capsules without the additional bonds with the hydrophobic domains formed gelatin. As a result, increases the concentration of F. assa-foetida carrier oil gelatin capsules are more compact and can store larger percentage of F. assa-foetida extract. Gelatin film from the skin of unicorn leatherjacket incorporated with essential oils [16] displayed excellent antibacterial activities, which similar to our results. The antibacterial activity which recognized in the essential oils from several medicinal plants established that the essential oils is related with the attack on the phospholipids present in the cell membranes, which causes increased permeability and leakage of cytoplasm, or in their interaction with enzymes located on the cell wall. Thus, the resistance of Gram-negative bacteria to the essential oils likely lay in the protective role of their cell wall lipopolysaccharide or outer membranes proteins, which restricts diffusion of hydrophobic compounds through its lipopolysaccharide layer [21].

Essential oils have the ability to disrupt lipid structure of the cell wall of bacteria, leading to destruction of cell membrane, cytoplasmic leakage, cell lysis and ultimately cell death. The decrease in $\mathrm{pH}$ that occurs due to cell 
membrane disruption resulted in a loss of control of cellular process such as ATP biosynthesis, DNA transcription and protein synthesis [22].F. assa-foetida essential oil gradually released from films to the solution and penetrates to the cell membranes and disrupts membrane structure and finally cell death. The nano-capsules as well as due to the risk of bacterial resistance stay safe. The nano-capsules according to the origin of the whole plant does not have any negative effects on the body.

\section{Acknowledgements}

This work was supported by the financial support from Shiraz University (grant No. 88-GRAGRST-108).

\section{Authors' Contributions}

All authors had equal role in design, work, statistical analysis and manuscript writing.

\section{Conflict of Interest}

The authors declare no conflict of interest.

\section{Funding/Support}

This study was supported by University of Shiraz.

\section{References}

1. Schrieber R, Gareis H. Gelatine handbook: theory and industrial practice. John Wiley and Sons, 2007.

2. Gómez-Guillén MC, Giménez B, López-Caballero ME, Montero MP. Functional and bioactive properties of collagen and gelatin from alternative sources: a review. Food Hydrocolloids. 2011;25(8):1813-27.

3. Gómez-Guillén MC, Turnay J, Fernández-Díaz MD, Ulmo N Lizarbe MA, Montero P. Structural and physical properties of gelatin extracted from different marine species: a comparative study. Food Hydrocolloids. 2002;16(1):25-34.

4. Rawdkuen S, Sai-Ut S, Benjakul S. Properties of gelatin films from giant catfish skin and bovine bone: a comparative study. Euro Food Res Technol. 2010;231(6):907-16.

5. Tharanathan RN. Biodegradable films and composite coatings: past, present and future. Trends Food Sci Technol. 2003;14(3):71-8.

6. Appendini P, Hotchkiss JH. Review of antimicrobial food packag- ing. Innovat Food Sci Emerg Technol. 2002;3(2):113-26.

7. Hanusová K, Dobiáš J, Klaudisová K. Effect of packaging films releasing antimicrobial agents on stability of food products. Czech J Food Sci. 2009;27:347-9.

8. Gómez-Guillén MC, Pérez-Mateos M, Gómez-Estaca J, López-Caballero E, Giménez B, Montero P. Fish gelatin: a renewable material for developing active biodegradable films. Trends Food Sci Technol. 2009;20(1):3-16.

9. Lucera A, Costa C, Conte A, Del Nobile MA. Food applications of natural antimicrobial compounds. Front Microbiol. 2012;3:287.

10. Solorzano-Santos F, Miranda-Novales MG. Essential oils from aromatic herbs as antimicrobial agents. Curr Opin Biotechnol. 2012;23(2):136-41.

11. Tajkarimi MM, Ibrahim SA, Cliver DO. Antimicrobial herb and spice compounds in food. Food Control.2010;21(9):1199-218.

12. Iranshahy $\mathbf{M}$, Iranshahi $M$. Traditional uses, phytochemistry and pharmacology of asafoetida (Ferula assa-foetida oleo-gumresin)-a review. J Ethnopharmacol. 2011;134(1):1-10.

13. Nazari ZE, Iranshahi M. Biologically active sesquiterpene coumarins from Ferula species. Phytother Res. 2011;25(3):315-23.

14. Ahmad M, Benjakul S, Prodpran T, Agustini TW. Physico-mechanical and antimicrobial properties of gelatin film from the skin of unicorn leatherjacket incorporated with essential oils. Food Hydrocolloids. 2012;28(1):189-99.

15. Bigi A, Cojazzi G, Panzavolta S, Rubini K, Roveri N. Mechanical and thermal properties of gelatin films at different degrees of glutaraldehyde crosslinking. Biomaterials. 2001;22(8):763-8.

16. Tongnuanchan P, Benjakul S, Prodpran T. Properties and antioxidant activity of fish skin gelatin film incorporated with citrus essential oils. Food Chem. 2012;134(3):1571-9.

17. Maneerung T, Tokura S, Rujiravanit R. Impregnation of silver nanoparticles into bacterial cellulose for antimicrobial wound dressing. Carbohydrate Polymers. 2008;72(1):43-51.

18. Kavoosi G, Rowshan V. Chemical composition, antioxidant and antimicrobial activities of essential oil obtained from Ferula assa-foetida oleo-gum-resin: effect of collection time. Food Chem. 2013;138(4):2180-7.

19. Aleman A, Giménez B, Montero P, Gómez-Guillén MC. Antioxidant activity of several marine skin gelatins. LWT - Food Sci Technol. 2011;44(2):407-13.

20. Oussalah M, Caillet S, Saucier L, Lacroix M. Inhibitory effects of selected plant essential oils on the growth of four pathogenic bacteria: E. coli O157:H7, Salmonella typhimurium, Staphylococcus aureus and Listeria monocytogenes. Food Cont. 2007;18(5):414-20.

21. Gomez-Estaca J, Lopez de Lacey A, Lopez-Caballero ME, GomezGuillen MC, Montero P. Biodegradable gelatin-chitosan films incorporated with essential oils as antimicrobial agents for fish preservation. Food Microbiol. 2010;27(7):889-96.

22. Xu J, Zhou F, Ji BP, Pei RS, Xu N. The antibacterial mechanism of carvacrol and thymol against Escherichia coli. Lett Appl Microbiol. 2008;47(3):174-9. 